\title{
Determination of Thermal Conductivity of Aloe in the Cooling and Thawing Process
}

\author{
Min Zhang ${ }^{1, *}$, Huizhong Zhao ${ }^{2}$, Zhiyou Zhong ${ }^{1}$, Jianhua Chen ${ }^{1}$, Zhenhua Che ${ }^{1}$, \\ Jiahua Lu ${ }^{1}$, and Le Yang ${ }^{1}$ \\ ${ }^{1}$ College of Food Sciences, Shanghai Ocean University, Shanghai, 201306, P.R. China \\ ${ }^{2}$ School of Environment and Architecture, University of Shanghai for Science and Technology, \\ Shanghai, 200093, P.R. China \\ zhangmeshou.edu.cn
}

\begin{abstract}
In this study, thermal conductivity of aloe was determined in the cooling process from $20^{\circ} \mathrm{C}$ to $-11^{\circ} \mathrm{C}$, and in the thawing process from $-11^{\circ} \mathrm{C}$ to $20^{\circ} \mathrm{C}$ using the tiny thermal probe method. The tiny thermal probe measurement system had the advantages of high accuracy, short test time, low temperature rise and little water removal and was found to give accurate and consistent experimental results. The results showed that the thermal conductivities increased with temperature over the freezing point. The thermal conductivities rapidly increased below the freezing point and it increased with the temperature decreasing. The thermal conductivities decreased with temperature below the thaw point. The thermal conductivities rapidly decreased over the thaw point and it decreased with temperature. The thermal conductivity of aloe in the cooling process was greater than that in the thawing process at the same temperature.
\end{abstract}

Keywords: Probe measurement system, Thermal conductivity, Temperature, Aloe.

\section{Introduction}

Aloe belongs to perennial evergreen succulent herb. It has been paid more and more attentions for its many functions such as medical, facial beauty, food, ornamental [1]. Quality of the aloe products depends on its storage and processing. In freezing and thawing processes, one of the most important properties to estimate the time is the thermal conductivity [2]. Some investigators have reported that the experimental values of thermal conductivity of fruits and vegetables over years [3], [4], [5], [6], [7], [8]. However, the thermal conductivity of aloe in the cooling and thawing process has never been reported in the literature.

In general, an extensive review of existing methods of measuring of thermal conductivity of food has been carried out by some researchers [9], [10], [11]. The thermal conductivity measurement methods can be classified into steady-state and unsteadystate methods [12]. The steady-state methods have the shortcoming of requiring a long time to equilibrate. Among various unsteady state methods, the line heat source

\footnotetext{
* Corresponding author.
} 
thermal conductivity probe is recommended for most food applications because it is simple, fast, convenient, cheaper and suitable for small sample size [3],[13]. In this work, an improved thermal conductivity probe system was used to determine the thermal conductivity of aloe in the cooling and thawing process. Advantages of this system are the short duration of the experiments, simplicity, high accuracy and relatively small sample requirement.

The objective of this work was to determine the thermal conductivity of aloe by a proposed probe measurement system in the cooling and thawing process.

\section{Materials and Methods}

\subsection{Materials}

The aloe leaves grown better were obtained from local market at Yangpu district of Shanghai, China. The homogeneity tissue in the middle of aloe leaves were chosen to determine because the tissue of aloe was different at various place. Three groups of aloe leaves bodies were placed in a constant temperature cabinet (Shanghai Precision Instrument CO., LHS-100CL, $\pm 0.5^{\circ} \mathrm{C}$ precision) of temperature from $-11^{\circ} \mathrm{C}$ to $20^{\circ} \mathrm{C}$ to ensure the initial temperature of sample was constant and uniform to facilitate the determination of thermal conductivity at different temperature conditions. Three replicates of each sample were used for each run and each run was repeated at least three times. The thermal conductivity values obtained were the average values of nine measurements under the same conditions.

\subsection{Method}

The probe measurement system which was based on the idealized non-steady state transient heat conduction model was proposed to determine the thermal conductivity of aloe tissue in the cooling process from $20^{\circ} \mathrm{C}$ to $-11^{\circ} \mathrm{C}$, and in the thawing process from $-11^{\circ} \mathrm{C}$ to $20^{\circ} \mathrm{C}$. The measurement system consisted of a designed thermal conductivity probe, DC power supply, multimeter (Keithley data acquisition), a constant temperature cabinet and controlled circuit system. A copper wire coated with a thin electrical insulation layer put inside the probe was used as heating element and measuring element in this experiment [14]. The probe was inserted into the measured aloe tissue which had been put into the constant temperature cabinet for four hours to keep a desired uniform temperature. An invariableness voltage was applied across the circuit system to cause the temperature rise of the copper wire inside the probe. This resulted in the temperature rise of probe tube and around aloe tissue in turn. The heat would transfer from the copper wire to the aloe tissue. As a result, the temperature of copper wire would change according to the correlation of copper resistance and its temperature. The weak output voltage signal from the electric bridge would be amplified and input the computer to be handled. And then the slope of output voltage and time of natural logarithm was obtained to calculate the thermal conductivity of aloe tissue according the equation (1)

$$
\lambda_{m}=-\frac{U^{3}}{R_{b}^{2}} C / \frac{\mathrm{d}(\Delta V)}{\mathrm{d}(\ln t)}
$$


Where $C=\frac{\alpha_{0} R_{0}}{64 \pi L}$ was instrument constant of the probe $(\Omega / \mathrm{mKs})$, which only related with the probe material, length and had nothing with the heating power and testing temperature of the testing system [15]. $\alpha_{0}$ was the copper electric resistance's temperature coefficient at $0^{\circ} \mathrm{C}\left(\mathrm{K}^{-1}\right) . R_{0}$ was the electric resistance value of the copper electric resistance at $0^{\circ} \mathrm{C}(\Omega) . L$ was the effective length of the probe $(\mathrm{m}) . \triangle V$ was the output electric voltage of the electric circuit (V). $t$ was heating time(s). $\lambda_{m}$ was the thermal conductivity of sample $(\mathrm{W} / \mathrm{mK})$. $U$ was the electric voltage of power supply (V). $R_{b}$ was the initial electric resistance value of probe $(\Omega)$.

The thermal conductivity probe apparatus had the merits of rapidity, accuracy, online measurement, and small sample requirement, which had been described by Zhang [16]. The apparatus was firstly calibrated with a sample of known thermal conductivity before testing thermal conductivity of aloe at different temperature. Here glycerin was chosen as the calibration sample for its higher viscosity. The thermal probe was inserted into the glycerin sample that filled the sample holder. The output voltage signal $\Delta V$ tested by the measurement system and was fed into a computer. And the curve of $\Delta V$-lnt could be drawn. According to the least-squares method, the slope of $\mathrm{d}(\Delta V) / \mathrm{d}(\ln t)$ could be obtained. Then the instrument constant of the probe could be obtained by Equation (1). The measurement accuracy of the apparatus was checked by determining thermal conductivities of ultra pure water (resistivity 18.4 $\mathrm{M} \Omega \bullet \mathrm{cm}$ ) at temperatures ranging from $-15^{\circ} \mathrm{C}$ to $20^{\circ} \mathrm{C}$. After the accuracy of the apparatus was tested, the thermal conductivities of aloe tissue in the cooling process were determined at desired temperatures from $20,10,5,3,1,-1,-3,-5,-7,-9^{\circ} \mathrm{C}$ to $-11^{\circ} \mathrm{C}$. Then the thermal conductivities of aloe tissue in the thawing process were determined at desired temperatures from $-9,-7,-5,-3,-1,1,3,5,10^{\circ} \mathrm{C}$ to $20^{\circ} \mathrm{C}$, respectively.

\section{Results and Discussions}

\subsection{Validation of Measurement System}

In order to validate the proposed method and the experimental design, the standard samples of water and ice were tested from $-15^{\circ} \mathrm{C}$ to $20^{\circ} \mathrm{C}$. Each sample was measured three times under the same conditions and the average value was calculated as thermal conductivity of the sample. An example of such profiles of output voltage was shown in Figure 1. The best fitting of the linear part of the output voltage-Ln (time) history was chosen optimizing the $R^{2}$ correlation coefficient, disregarding the initial and the final points. During the experiments, the maximum temperature rise of the heated probe was controlled within $2^{\circ} \mathrm{C}$.

The experimental results were shown in Figure 2 with comparison to the recommended values [17]. The results showed the agreement between the measured and the recommended values. The maximum of relative error with reference values was $2.93 \%$ and the mean relative error was $1.51 \%$. The accuracy of the measuring apparatus was satisfactorily accepted in this experiment. 


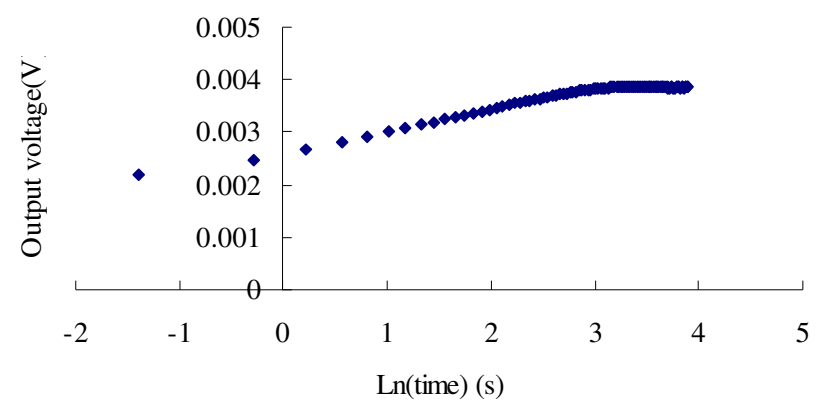

Fig. 1. Output voltage and temperature rise profiles in the measurement

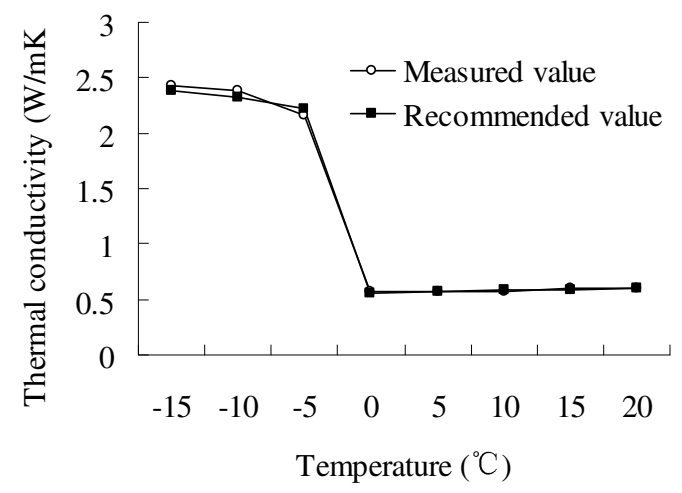

Fig. 2. Comparison of measured and recommended values of pure water

\subsection{Measured Thermal Conductivities of Aloe in the Cooling and Thawing Process}

Using the calibrated probe measurement apparatus, the thermal conductivities of aloe tissue were determined in the cooling process from $20^{\circ} \mathrm{C}$ to $-11^{\circ} \mathrm{C}$ and in the thawing process from $-11^{\circ} \mathrm{C}$ to $20^{\circ} \mathrm{C}$. The tested thermal conductivities of aloe were showed in Figure 3. The thermal conductivity of normal aloe issue which was not subjected to the frozen injury was bigger than that of denatured aloe issue which had been subjected to frozen injury at the same temperature.

The developing tendency of thermal conductivity of aloe in the cooling process and in the thawing process was shown as Figure 4 and Figure 5. In the cooling process, it showed that the thermal conductivities decreased with temperature dropping over the freezing point, and rapidly increased at the freezing point. The thermal conductivities increased with the temperature dropping below the freezing point. Because the water is the main component of aloe tissue, the thermal properties of aloe were similar to that of water. The thermal conductivity of water decreased with temperature dropping over the freezing. The thermal conductivity of water increased at the freezing point because of appearance of phase transition. Thermal conductivity of ice decreased with 


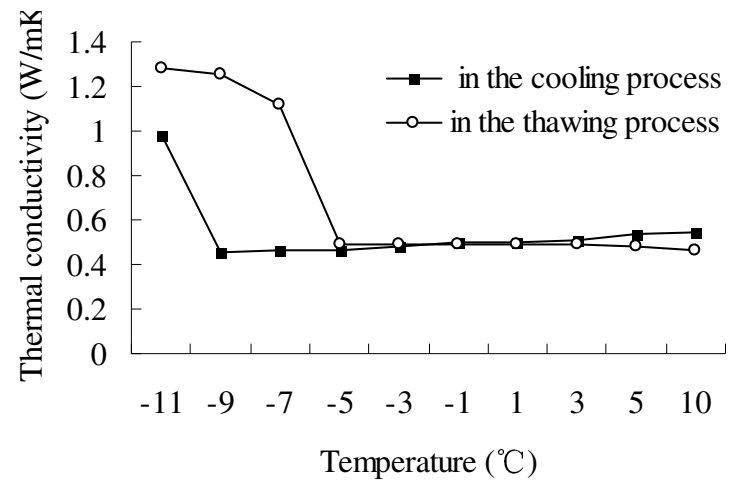

Fig. 3. Determined thermal conductivities of aloe

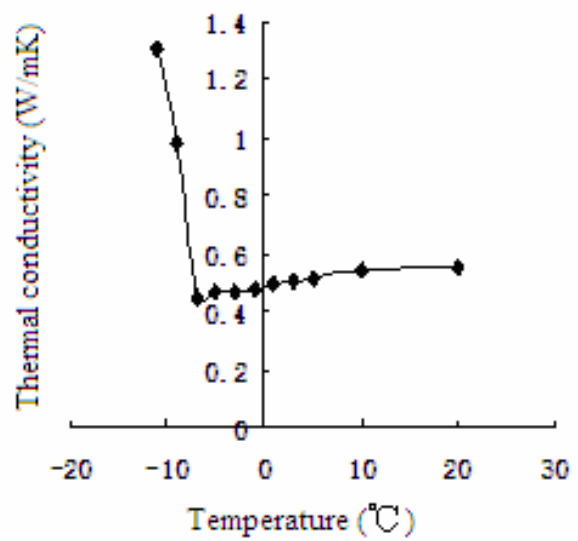

Fig. 4. Determined thermal conductivities of aloe in the cooling process

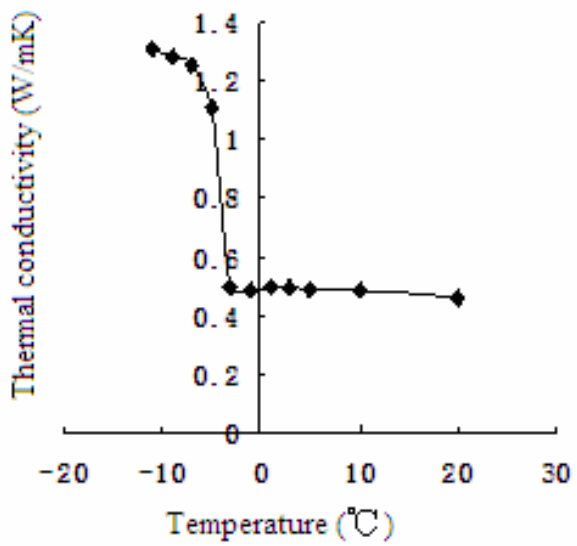

Fig. 5. Determined thermal conductivities of aloe in the thawing process 
the temperature increasing. Variation of thermal conductivity of water within aloe tissue influenced the variation of the thermal conductivity of aloe. In the thawing process, it showed that the thermal conductivities decreased with the temperature increasing below the thaw point, which was similar to that of in the cooling process. But over the thaw point, the thermal conductivities decreased with the temperature increasing over the thaw point, which was different with that of in the cooling process. It was probably for the extreme dehydration of cytoplasm of aloe tissue. The protein structure and the membrane system in the aloe cell were damaged. It resulted in water loss of aloe tissue in the thawing process.

\section{Conclusion}

The proposed tiny heat probe test system allowed accurate and reliable measurement of thermal conductivity in a given range to be obtained, which was used to determine the thermal conductivities of aloe at different temperatures from $-11^{\circ} \mathrm{C}$ to $20^{\circ} \mathrm{C}$. The results showed that the thermal conductivities increased with temperature over the freezing point. The thermal conductivities rapidly increased below the freezing point and it increased with the temperature decreasing. The thermal conductivities decreased with temperature below the thaw point. The thermal conductivities rapidly decreased over the thaw point and it decreased with temperature. The thermal conductivity of aloe in the cooling process was greater than that in the thawing process at the same temperature and gave an explanation from the changes in tissue microstructure. These studies could give help to the storage and processing, the engineering calculations in the course of freezing of aloe, and give foundations for the future study of the impact of frost on the aloe.

Acknowledgments. Funding for this research was provided by the Natural Science Foundation of China, Grant No 30771245 and Leading Academic Discipline Project of Shanghai Municipal Education Commission, Project No J50704.

\section{References}

1. Che, G., Qi, H.L., Yang, H.T., Wan, L.: Journal of Heilongiiang First Land Reclamation University 19, 47 (2007) (in Chinese)

2. Delgado, A.E., Gallo, A., De Piante, D., Rubiolo, A.: Journal of Food Engineering 31, 137 (1997)

3. Sweat, V.E.: Engineering properties of foods. Marcel Dekker, New York (1995)

4. Rahman, S.: Food Properties Handbook. CRC Press, Boca Raton (1995)

5. Liang, X.G., Zhang, Y.P., Ge, X.S.: Meas. Sci. Technol. 10, 82 (1999)

6. Saravacos, G.D., Maroulis, Z.B.: Transport properties of foods. Marcel Dekker, New York (2001)

7. Ali, S.D., Ramaswamy, H.S., Awuah, G.B.: Journal of Food Process Engineering 25, 417 (2002)

8. Martins, R.C., Silva, C.L.M.: Journal of Food Engineering 63, 383 (2004)

9. Blackwell, J.H.: J. Appl. Phys. 25, 137 (1954)

10. Reidy, G.A., Rippen, A.L.: Trans. ASAE 14, 248 (1971) 
11. Choi, Y., Okos, M.R.: Transaction of ASAE 26, 305 (1983)

12. Nesvadba, P.: Journal of Food Engineering 1, 93 (1982)

13. Carson, J.K., Lovatt, S.J., Tanner, D.J.: Predicting the effective thermal conductivity of unfrozen, porous foods. Journal of Food Engineering 75, 297 (2006)

14. Cheng, S.X., Jiang, Y.F., Liang, X.G.: Meas. Sci. Technol. 5, 1339 (1994)

15. Zhang, H.F., Zhao, G., Ye, H., Ge, X.S., Cheng, S.X.: Meas. Sci. Technol. 16, 1430 (2005)

16. Zhang, M., Zhao, H.Z., Xie, J., Sun, Z.Q., Zhang, B.L.: Journal of Agricultural Machinery 37, 90 (2006) (in Chinese)

17. Chen, Z.S., Ge, X.S., Gu, Y.Q.: Thermophysical Property Measurement. USTC Press, Hefei (1990) (in Chinese) 